\title{
Using open software to teach resource assessment of solar thermal and geothermal energy
}

Ulazia, Alain ${ }^{\mathrm{c}}$; Urresti, Aitor ${ }^{\mathrm{b}}$, Antxustegi, M. Mirari ${ }^{\mathrm{a}}$; Gonzalez Alriols, Maria ${ }^{\mathrm{a}}$; Campos-Celador, Alvaro ${ }^{\mathrm{b}}$; Ibarra-Berastegi, Gabriel ${ }^{\mathrm{c}}$.

${ }^{a}$ Departament of Chemical Engineering and Enviroment, University of Basque Country UPV/EHU.; ${ }^{b}$ Department of Thermal Machines and Engines, University of Basque Country UPV/EHU.;'Department of Nuclear Engineering and Fluid Mechanics, University of Basque Country UPV/EHU.

\begin{abstract}
The students of the Faculties of Engineering of the Universitty of Basque Country (Gipuzkoa-Eibar) in the last years of their studies, before becoming engineers, have the opportunity to select a block of subjects intended to enhance their knowledge on renewable energy systems. One of these subjects is Solar Thermal and Geothermal energy. These subjects are devoted to assessing the renewable energy resource, and designing optimal systems. Apart from the transmission of good practices, the focus is practical and is based on hands-on computer real-life exercises, which involves not only intensive programming using high-level software, but also the spatial representation of results. To that purpose two main open source codes are used: Octave (https://www.gnu.org/softwareloctave/), and QGIS (https://www.qgis.org/). Students learn how to address real-life problems regarding the geographical representation of solar radiation and low temperature geothermal resources using QGIS, and solar thermal system modelling using Octave.
\end{abstract}

Keywords: QGIS; Octave; learning by projects. 


\section{Introduction}

During the last two years, students at Gipuzkoa-Eibar Faculty of Engineering in the Grade of Engineering for Renewable Energies (4 years) have many specialization subjects (http://www.ehu.eus/es/web/eibar). We will expose "Solar Thermal and Geothermal Energy" (third year), because of its interest in terms of the use of open software for the analysis of renewable energy resource and its geographical and spatial distribution. We must underline that the surveys of the students about the subject are generally outstanding.

The subject is divided in two different parts, each one related to solar thermal and geothermal energy, together with a last chapter related to the coupling of both technologies. The teacher uses learning by projects techniques, which involve the practical design of solar thermal and low temperature geothermal systems.

- Solar Thermal Energy: The software for geographical information systems QGIS is a powerful instrument for the analysis solar radiation resources. We use satellite radiation data to evaluate the solar resource, together with LIDAR data to evaluate the shading patterns. Octave is also used to simulate the thermal behaviour of solar thermal collectors under varying thermal conditions.

- Low Temperature Geothermal Energy: The ability of geographical information systems like QGIS, to manipulate geographical data is very useful for the representation of lithography, and the manipulation of energy extraction surfaces.

This includes handling two groups of skills:

1. Solving real-life problems like the correct design of the solar collection field, simulating the thermal behaviour of solar collectors under varying thermal conditions, and serial/parallel connection schemes. This implies the use of highlevel programming software like Octave.

2. Spatial planning and geographical characterization of available energy resources. This implies the use of a geographical information system (GIS) software.

\section{Method}

When students select our subject in their third year of studies they have a reasonable degree of computing programming skills and they are already somehow familiar with general purpose software like VisualBasic, Fortran or C++. Due to this initial background, it is possible for the team of teachers to design classes as a set of practical exercises within a bigger resource analysis project. The software we use in classes are Octave, and QGIS. 


\subsection{Octave}

Octave is a high-level programming language intended for numerical computations, that can be very useful for solving sets of linear equations and dynamic models like the ones related to simulate the thermal behaviour of solar collectors. It is freely distributed under the GNU General Public License, and runs on most operating systems, like GNU/Linux, $\mathrm{BSD}$, macOS, and Windows. It is largely compatible with Matlab, one of the most extendedly used numerical computation programs. It offers a fully integrated graphical user interface, and data visualization tools.

Additionally, Octave can be extended with new modules and functions already available, and the possibility of developing new functions. This way, Octave can be completely augmented and adapted to different objectives.

\subsection{QGIS}

QGIS is an official project of the Open Source Geospatial Foundation (OSGeo). QGIS provides a continuously growing number of capabilities provided by core functions and plugins. You can visualize, manage, edit, analyse data, and compose printable maps. Get a first impression with a more detailed feature list. This specific software for geographic information systems (GIS) purposes offers a more visual interface than R for geographical representation and spatial analysis. It can be a good complement of $\mathrm{R}$ to obtain a more understandable design in the presentation of maps, and to facilitate more visual operations than rough codes and scripts needed in $\mathrm{R}$.

\subsection{Learning by problems and learning by projects}

Using Octave and QGIS to introduce concepts related to the subjects mentioned above, represents for our students a real and pragmatic way of problem solving. Taking into account Bloom's (1956) Taxonomy of Educational Objectives for Skills-Based Goals, they get a high level of expertise on 'guided response' and 'mechanism': 1) the student knows the steps required to complete the task, and 2) performs the tasks in a confident, proficient and habitual manner. The student simulates what the scientists do every day and use the logic of discovery instead of the logic of justification (Hanson, 1958). As Clement states (Clement 1988, 2008) in his deep study on scientific creativity, when dealing with a problem heuristically there is no difference between the problem solving capacity of an expert and of a student. That is, the students should know the real scientific practice, and not only the final important and supposedly finished theories (Chi et al., 1981, 1989). The state of the art in this domain has been developed very deeply in constructive problem solving via the use of analogy, visual thinking, spatial abstraction and other different heuristic instruments have been pointed out for that (Welsh 2012, Simons 1993, Newel 
1972). We will show that the mentioned software is a powerful instrument to implement this heuristics understood as the art for solving problems.

\section{Results: examples}

\subsection{Octave for solar collector simulation}

Students learn to read relevant climatic information from publicly available repositories, mostly solar radiation and outside air temperature. They learn how to simulate solar collector fields, using collector performance parameters, and surrounding environmental conditions. For example, Fig. 1 shows the variation of the thermal performance of solar collectors varying incident solar radiation and temperature difference. Fig 2 shows the evolution of temperature difference in a solar collector and performance related to water flow rate.

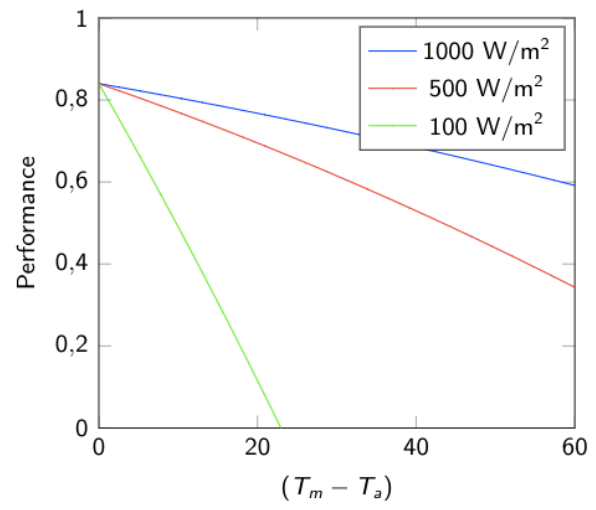

Fig. 1. Performance related to climatic conditions

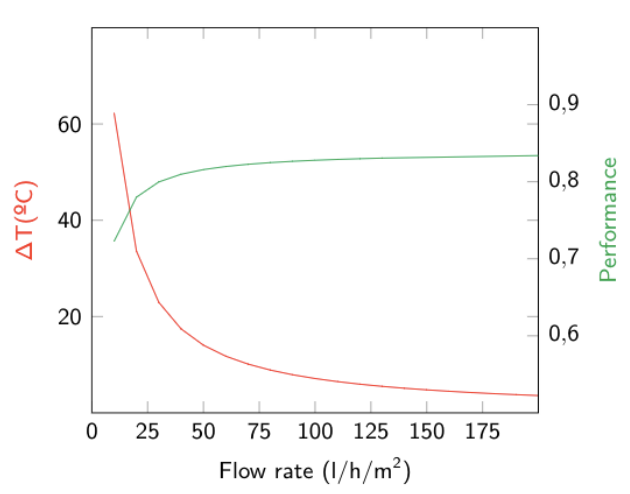

Fig. 2. Performance related to flow rate

Students learn to simulate solar collector fields, and get a deeper understanding of the parameters that influence the thermal performance of the collectors, or the outgoing temperature of water.

\subsection{QGIS for solar energy resource}

In this case, geographic information systems (GIS) are very useful to place the information available and relate it to the surrounding conditions. Students learn to load and use publicly available information and to manage it to obtain useful information for their projects.

For example, Fig. 3 shows the thermal radiation for the Deba river's basin, obtained from satellite data. 


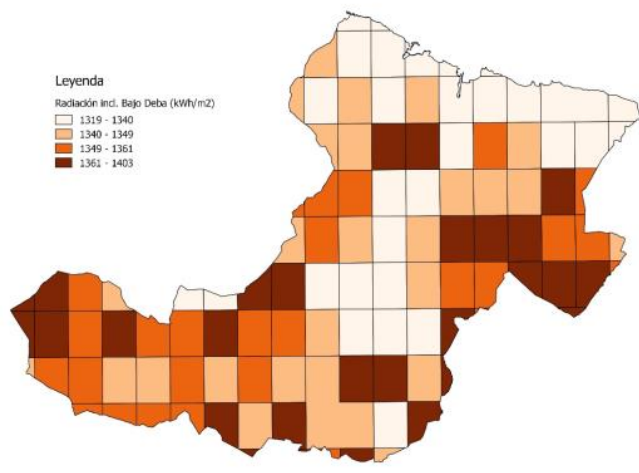

Fig. 3. Solar radiation from satellite data

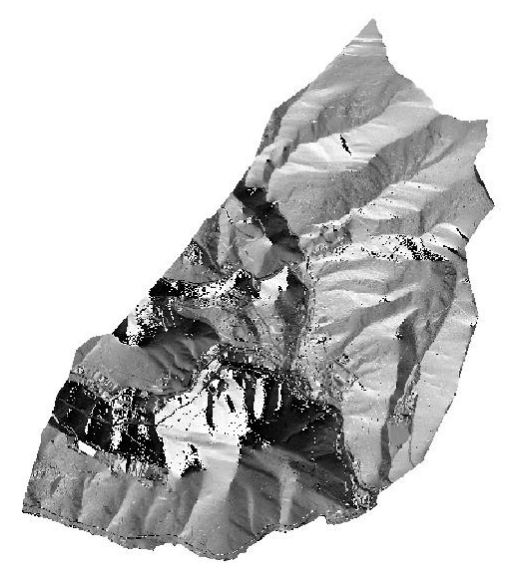

Fig. 5. Slope orientation for Ermua, from LIDAR data

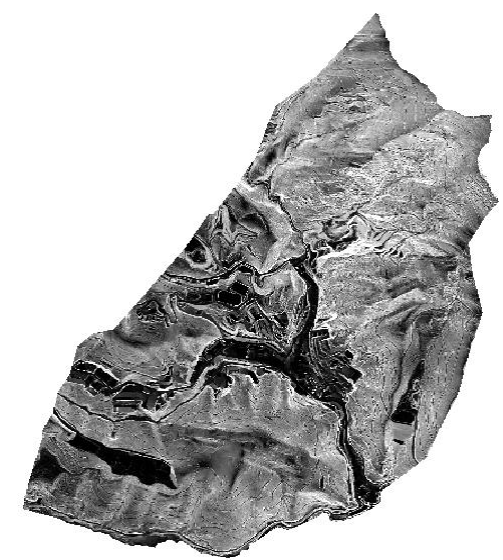

Fig. 4. Inclination map for Ermua, from LIDAR data

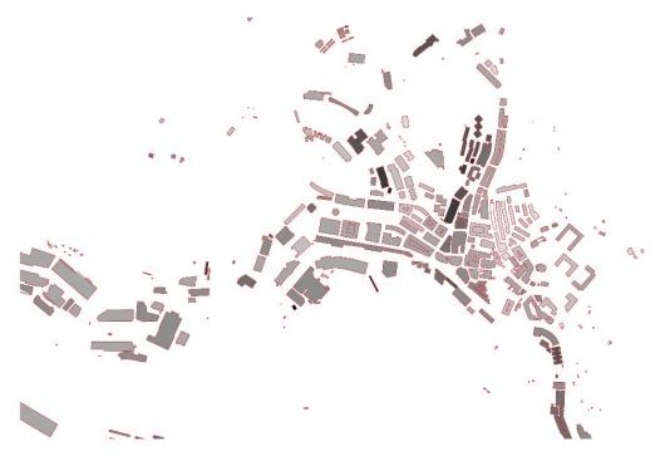

Fig. 6. Roof shading factor for Ermua

QGIS can also be used to calculate useful data from the available information. Using the r.sun integrated function, QGIS can be used to load inclination maps (Fig. 4), and slope orientation maps (Fig.5) from LIDAR data, to calculate the annual shading factors for roofs, as shown in Fig.6.

\subsection{QGIS for geothermal resource}

Geographic Information Systems are also very useful to quantify the low temperature geothermal resource. Lithology and surface calculations are the basis of the assessment of geothermal heat transfer capabilities.

Students can download the lithological information from public resources, load it to QGIS, as shown in Fig. 7, and use it for a first assessment of the most suitable areas for geothermal systems. 


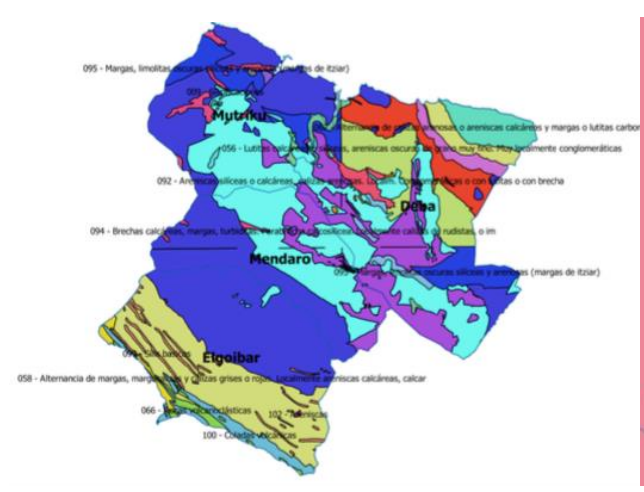

Fig. 7. Lithology for the town of Mendaro

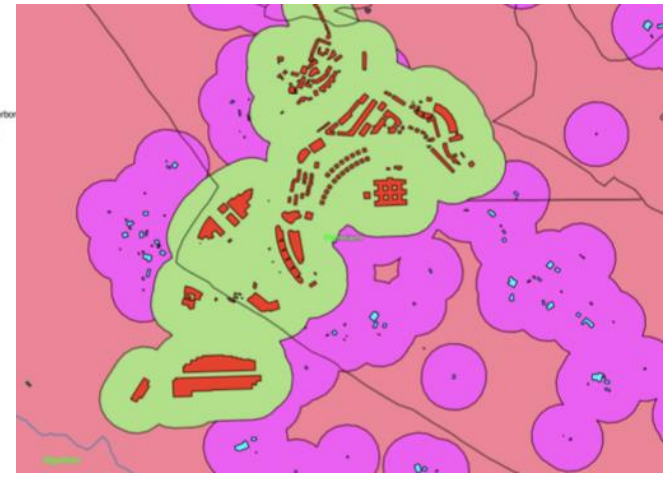

Fig. 8. Surface calculation around buildings

Surface area calculations is also very useful for the assessment of the accessible geothermal resource. Since low temperature geothermal energy is a low quality resource, it can only be exploited in the nearby of buildings. The buffering tools of QGIS can be used to evaluate the area in the surrounding of buildings, as can be seen in Fig 8. Overlapping the lithological information with the accessible area, and usual conversion factor can yield the usable geothermal potential.

\section{Results in the classroom and conclusions}

We have applied these learning by projects techniques in the Grade of Engineering for Renewable Energies for the last four years in the subject of "Solar Thermal and Geothermal Energy". Taking into account that there are approximately 70 students per course we are speaking about more than 250 students, which have shown very good opinions in their surveys when they have been questioned about these subjects and the teaching methods used. For example, last years the teacher of the subject obtained 4.1 out of 5 .

The introduction of the mentioned software has enhanced our learning by problems perspective with respect to previous more theoretical and expositive way of teaching. Previously the subject was focused only on learning by projects methodology, and more specifically on the final design of a solar thermal system and the final design of a geothermal system. The students would choose a location at which they would design the systems, with no additional information.

With the use of these new software tools, students can perform a first analysis in order to obtain the best roofs to install solar thermal energy, using the roof shading factor as shown in figure 6, or the best soils for geothermal applications as shown in figures 7 and 8 .

Moreover, the use of Octave for solar thermal applications allows the teacher to introduce learning by problems methodology, in order to enhance the understanding of the thermal behaviour of solar collectors. The simulation of solar collectors and solar collector fields 
can be used to understand the way the collectors react under severe conditions like overheating or freezing, or the importance of factors such as flow rate, outer temperature, or circulating temperature. This way, students can also compare the behaviour of different collectors, and choose the ones best suited to their needs.

As a conclusion, the introduction of these new software tools, together with the use of freely available databases, allow the teachers to broaden the scope of the subjects, introducing new learning by problems techniques, and enhancing the self-learning abilities of the students.

\section{References}

Bloom, B. S. (1956). Taxonomy of Educational Objectives. New York: David McKay.

Clement, J. (1988). Observed methods for generating analogies in scientific problem solving. Cognitive Science, 12(4), 563-586.

Clement, J. (2008). Creative model construction in scientists and students: The role of imagery, analogy, and mental simulation. Springer Science \& Business Media.

Chi, M. T., Feltovich, P. J., \& Glaser, R. (1981). Categorization and representation of physics problems by experts and novices. Cognitive science, 5(2), 121-152.

Chi, M. T., Bassok, M., Lewis, M. W., Reimann, P., \& Glaser, R. (1989). Selfexplanations: How students study and use examples in learning to solve problems. Cognitive science, 13(2), 145-182.

Hanson, N. R. (1958). The logic of discovery. The Journal of Philosophy, 1073-1089.

Newell, A., \& Simon, H. A. (1972). Human problem solving (Vol. 104, No. 9). Englewood Cliffs, NJ: Prentice-Hall.

Simons, P. R. J. (1993). Constructive learning: The role of the learner. In Designing environments for constructive learning (pp. 291-313). Springer Berlin Heidelberg.

Welsh, T. M. (2012). Designing environments for constructive learning (Vol. 105). T. M. Duffy, J. Lowyck, \& D. H. Jonassen (Eds.). Springer Science \& Business Media. 